\title{
Article
}

\section{Diminazene Aceturate Stabilizes Atherosclerotic Plaque and Attenuates Hepatic Steatosis in apoE-Knockout Mice by Influencing Macrophages Polarization and Taurine Biosynthesis}

\author{
Aneta Stachowicz ${ }^{1, *} \mathbb{0}$, Anna Wiśniewska ${ }^{1} \mathbb{D}$, Katarzyna Kuś $^{1}$, Magdalena Białas ${ }^{2}$, Magdalena Łomnicka ${ }^{1}$, \\ Justyna Totoń-Żurańska ${ }^{1}{ }^{\circledR}$, Anna Kiepura ${ }^{1}{ }^{\circledR}$, Kamila Stachyra $^{1}$, Maciej Suski ${ }^{1}{ }^{\circledR}$, Beata Bujak-Giżycka ${ }^{1}$, \\ Jacek Jawień ${ }^{1}{ }^{1}$ and Rafał Olszanecki ${ }^{1}$
}

1 Faculty of Pharmacy, Jagiellonian University Medical College, 31-531 Krakow, Poland; anna.niepsuj@uj.edu.pl (A.W.); katarzyna.1.kus@uj.edu.pl (K.K.); m.lomnicka@uj.edu.pl (M.Ł.); justyna.toton-zuranska@uj.edu.pl (J.T.-Ż.); a.kiepura@uj.edu.pl (A.K.); kamila.stachyra@uj.edu.pl (K.S.); maciej.suski@uj.edu.pl (M.S.); beata.bujak-gizycka@uj.edu.pl (B.B.-G.); jacek.jawien@uj.edu.pl (J.J.); rafal.olszanecki@uj.edu.pl (R.O.)

2 Faculty of Pharmacy, Jagiellonian University Medical College, 31-531 Krakow, Poland; magdalena.bialas@uj.edu.pl

check for

updates

Citation: Stachowicz, A.;

Wiśniewska, A.; Kuś, K.; Białas, M.;

Łomnicka, M.; Totoń-Żurańska, J.;

Kiepura, A.; Stachyra, K.; Suski, M.; Bujak-Giżycka, B.; et al. Diminazene Aceturate Stabilizes Atherosclerotic Plaque and Attenuates Hepatic Steatosis in apoE-Knockout Mice by Influencing Macrophages Polarization and Taurine Biosynthesis. Int. J. Mol. Sci. 2021, 22, 5861.

https://doi.org/10.3390/ijms22115861

Academic Editor: Ida

Daniela Perrotta

Received: 28 April 2021

Accepted: 25 May 2021

Published: 30 May 2021

Publisher's Note: MDPI stays neutral with regard to jurisdictional claims in published maps and institutional affiliations.

Copyright: (c) 2021 by the authors. Licensee MDPI, Basel, Switzerland. This article is an open access article distributed under the terms and conditions of the Creative Commons Attribution (CC BY) license (https:/ / creativecommons.org/licenses/by/ $4.0 /)$.
* Correspondence: aneta.stachowicz@uj.edu.pl

\begin{abstract}
Atherosclerosis and nonalcoholic fatty liver disease are leading causes of morbidity and mortality in the Western countries. The renin-angiotensin system (RAS) with its two main opposing effectors, i.e., angiotensin II (Ang II) and Ang-(1-7), is widely recognized as a major regulator of cardiovascular function and body metabolic processes. Angiotensin-converting enzyme 2 (ACE2) by breaking-down Ang II forms Ang-(1-7) and thus favors Ang-(1-7) actions. Therefore, the aim of our study was to comprehensively evaluate the influence of prolonged treatment with ACE2 activator, diminazene aceturate (DIZE) on the development of atherosclerotic lesions and hepatic steatosis in apoE ${ }^{-/-}$mice fed a high-fat diet (HFD). We have shown that DIZE stabilized atherosclerotic lesions and attenuated hepatic steatosis in $\mathrm{apoE}^{-/-}$mice fed an HFD. Such effects were associated with decreased total macrophages content and increased $\alpha$-smooth muscle actin levels in atherosclerotic plaques. Moreover, DIZE changed polarization of macrophages towards increased amount of antiinflammatory M2 macrophages in the atherosclerotic lesions. Interestingly, the anti-steatotic action of DIZE in the liver was related to the elevated levels of HDL in the plasma, decreased levels of triglycerides, and increased biosynthesis and concentration of taurine in the liver of apoE $\mathrm{E}^{-/-}$mice. However, exact molecular mechanisms of both anti-atherosclerotic and anti-steatotic actions of DIZE require further investigations.
\end{abstract}

Keywords: atherosclerosis; fatty liver; DIZE; macrophages polarization; apoE-knockout mice; ACE21

\section{Introduction}

Atherosclerosis and nonalcoholic fatty liver disease (NAFLD) are leading causes of morbidity and mortality in the Western countries [1]. Atherosclerosis, a multifactorial inflammatory illness of arteries, is characterized by a lipid-rich necrotic core and a ruptureprone fibrous cap. The rupture of the atherosclerotic plaque can cause life-threatening complications: coronary artery disease, stroke, peripheral artery disease, and myocardial infarction [2]. Endothelial activation is an initial step of atherogenesis that promotes the accumulation of oxidized low-density lipoproteins (ox-LDL), monocytes, and other inflammatory cells in the subendothelial space. Subsequently, the engulfment of ox-LDL by macrophages, exacerbation of inflammation, migration and activation of vascular smooth muscle cells (VSMC), and finally, apoptosis of macrophages and VSMC occurs [3,4]. Mounting evidence indicates that NAFLD, which is manifested by triglyceride accumulation 
in the hepatocytes, is an important independent risk factor for atherogenesis [5]. It encompasses a variety of pathological conditions, such as simple hepatic steatosis, steatosis with inflammatory response-nonalcoholic steatohepatitis (NASH), cirrhosis and fibrosis, and hepatocarcinoma [6]. The pathogenesis of NAFLD could be described by classical "two hit-hypothesis", where initial lesions in the liver are caused by excess accumulation of free fatty acids, while further damage and subsequent inflammation and fibrosis are triggered by oxidative stress and proinflammatory cytokines [7]. The renin-angiotensin system (RAS) is widely recognized as a major regulator of cardiovascular function and body metabolic processes [8,9]. The classical axis of RAS, i.e., angiotensin-converting enzyme (ACE)/Ang II/AT1 has been shown to contribute to the development of atherosclerosis and NAFLD $[10,11]$. Angiotensin II (Ang II), which is a product of the conversion of Ang I by ACE, has pro-oxidant, proinflammatory, and prothrombotic properties. It increases vascular permeability, oxidation and uptake of LDL, inflammatory cell infiltration, and generation of reactive oxygen species [12,13]. Ang II action is counteracted by Ang-(1-7), which is produced from Ang II by ACE2. It has been reported that ACE2/Ang-(1-7)/Mas axis had atheroprotective effects as well as inhibited hepatic insulin resistance, improved glucose uptake, and decreased glycogen synthesis [14,15]. Indeed, overexpression of ACE2 attenuated atherosclerosis and enhanced atherosclerotic plaque stability in a rabbit model of atherogenesis, and contrarily, its genetic deficiency worsened atherosclerosis in apoE-knockout mice $[16,17]$. Additionally, deletion of ACE2 in mice aggravates hepatic steatosis, inflammation, and oxidative stress [18]. Taking into account the role of ACE2 in cardiovascular and metabolic processes, its pharmacological activation might have the beneficial effects in the treatment of atherosclerosis and NAFLD. In 2011, it was shown that diminazene aceturate (DIZE) has an ability to increase ACE2 activity. DIZE is an aromatic diamidine approved by the US Food and Drug Administration for the treatment of human trypanosomiasis, but almost for six decades, it is used mainly as an antitrypanosomal drug in animals. The drug is well known and devoid of major toxic effects, thus may be a good candidate for repurposing [19]. Noteworthy, it has been shown that DIZE could attenuate pulmonary hypertension, myocardial infarction, and type 1 diabetes and reduce adiposity [20-22]. DIZE was recently shown to attenuate post-myocardial infarction contractile and electrophysiological dysfunction [23]. Interestingly, DIZE has been also proposed as a potential drug to prevent novel severe acute respiratory syndrome coronavirus 2 (SARS-CoV-2) complications. All these data make DIZE an interesting drug candidate with new indications.

Apolipoprotein E-knockout (apoE ${ }^{-/-}$) mice that spontaneously develop atherosclerotic lesions, hypercholesterolemia, and dyslipidemia are a popular animal model of atherosclerosis. Along with atherosclerotic plaques, they also exhibit mild hepatic steatosis, which is more exacerbated in mice on a high-fat diet. Thus, the aim of our study was to comprehensively evaluate the influence of prolonged treatment with ACE2 activator, diminazene aceturate (DIZE), on the development of atherosclerotic lesions and hepatic steatosis in $\mathrm{apoE}^{-/-}$mice fed a high-fat diet (HFD).

\section{Results}

\subsection{Influence of DIZE on Atherosclerosis Progression}

To evaluate the impact of DIZE on the development of atherosclerosis, we treated apoE ${ }^{-/-}$mice fed a high-fat diet with DIZE (30 mg per $\mathrm{kg}$ of body weight per day) for 16 weeks. The treatment neither caused significant decrease in atherosclerotic lesions in the aorta of apoE ${ }^{-/-}$mice as measured by "cross-section" method $(266,550 \pm 19,271$ vs. $284,551 \pm 13,070 \mu^{2} ; p>0.05$ ) (Figure $1 \mathrm{~A}-\mathrm{C}$ ) nor reduced the necrotic core in atherosclerotic plaques $(12.9 \% \pm 1.5 \%$ vs. $10.1 \% \pm 0.6 \% ; p<0.05)$ (Figure $1 \mathrm{D}-\mathrm{F})$. However, DIZE administration stabilized atherosclerotic lesions in apo $\mathrm{E}^{-/-}$mice: it significantly decreased the macrophages content as evidenced by CD68 staining $(30.7 \% \pm 1.1 \%$ vs. $42.6 \% \pm 1.7 \% ; p<0.05$ ) (Figure $2 \mathrm{~A}-\mathrm{C}$ ) and increased the smooth muscle $\alpha$-actin (SMA) content $(5.4 \% \pm 0.6 \%$ vs. $3.4 \% \pm 0.4 \% ; p<0.05)$ (Figure $2 \mathrm{D}-\mathrm{F})$. It seems that DIZE action 
was associated with increased mRNA expression of ACE2 enzyme, but not ACE and neprilysin (NEP) enzymes, in the aorta of apoE ${ }^{-/-}$mice (Figure 1G).

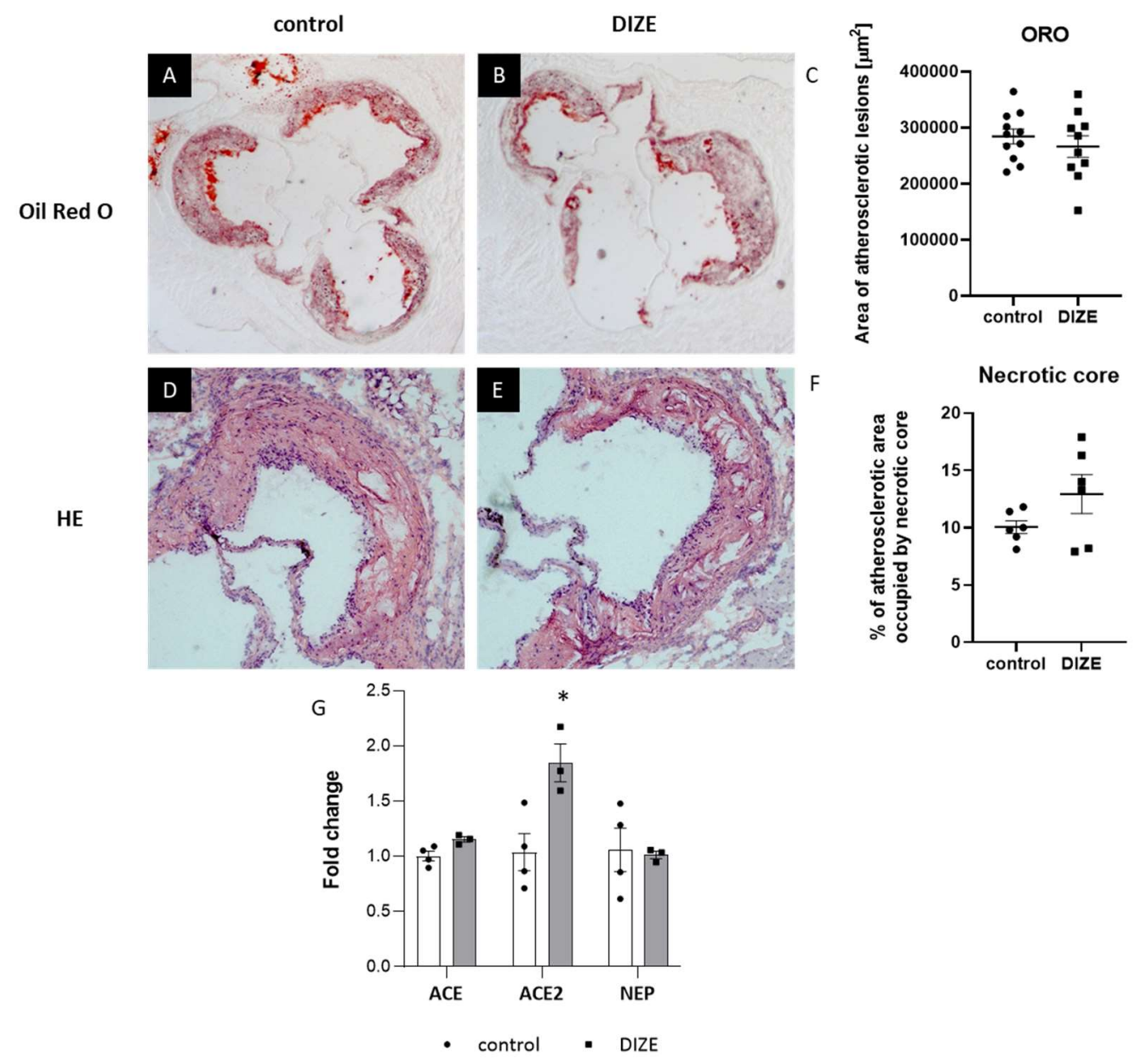

Figure 1. Influence of DIZE on atherosclerosis progression. Representative micrographs showing oil-red O-stained atherosclerotic lesions (A,B) and HE-stained necrotic cores (D,E) in the aorta of control and DIZE-treated mice as well as their corresponding quantitative analyses $(\mathbf{C}, \mathbf{F})$. mRNA expression of ACE, ACE2, and NEP in the aorta of control and DIZE-treated mice (G). Data are mean \pm SEM analyzed using $t$-test $\left({ }^{*} p<0.05\right.$ as compared to control; $n=3-11$ per group).

To further explore the reduced number of macrophages after DIZE administration, we checked whether DIZE can change the content of proinflammatory M1 and antiinflammatory M2 phenotypes of macrophages in atherosclerotic plaques. Interestingly, treatment with DIZE led to the elevated level of M2 macrophages $(10.8 \% \pm 1.7 \%$ vs. $5.7 \% \pm 1.4 \% ; p<0.05$ ) (Figure $3 \mathrm{~A}-\mathrm{C}$ ) in atherosclerotic lesions of apoE ${ }^{-/-}$mice, but did not change the content of M1 macrophages $(24.1 \% \pm 2.5 \%$ vs. $27.4 \% \pm 2.4 \% ; p>0.05)$ (Figure 3D-F). To confirm those results, we performed in vitro experiments of polarization of THP-1 macrophages to M1 and M2 phenotypes in presence of DIZE $(10 \mu \mathrm{M})$. Indeed, DIZE treatment led to 2 times increased level of the one of anti-inflammatory M2 markers (Fc Fragment of IgE Receptor II, FCER2) in THP-1 macrophages stimulated with IL-4 (Figure $3 \mathrm{H}$ ). Surprisingly, it also significantly elevated mRNA expression of proinflammatory M1 markers (IL-1 $\beta$ and TNF- $\alpha$ ) in THP-1 macrophages stimulated with LPS (Figure 3G). 

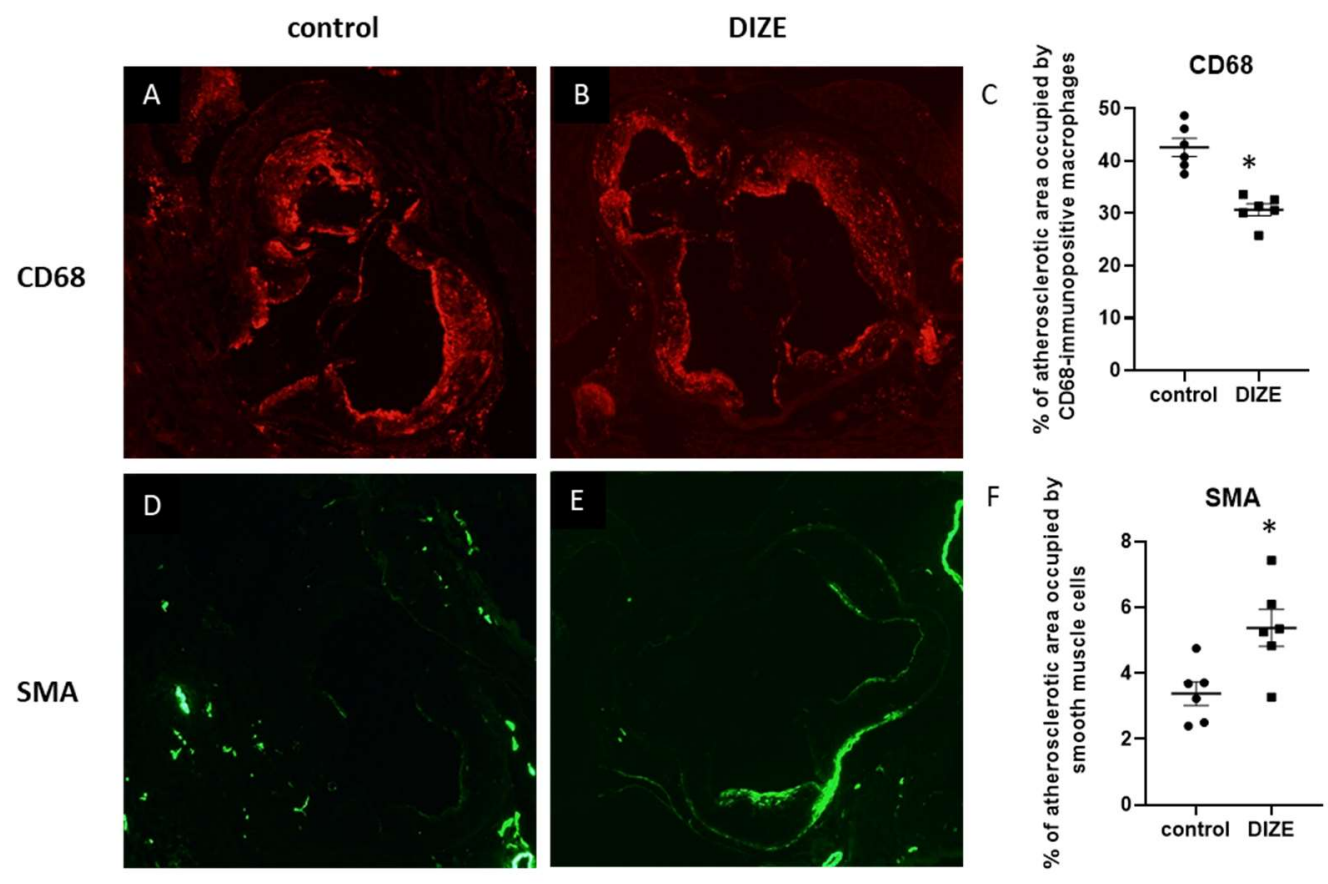

\begin{tabular}{lcccc}
\hline G & $\begin{array}{c}\text { Total } \\
\text { cholesterol } \\
{[\mathbf{m m o l} / \mathbf{L}]}\end{array}$ & $\begin{array}{c}\text { HDL } \\
{[\mathbf{m m o l} / \mathbf{L}]}\end{array}$ & $\begin{array}{c}\text { LDL } \\
{[\mathbf{m m o l} / \mathbf{L}]}\end{array}$ & $\begin{array}{c}\text { TG } \\
{[\mathbf{m m o l} / \mathbf{L}]}\end{array}$ \\
\hline apoE $^{-/-}(\mathbf{H F D})$ & $27.24 \pm 4.49$ & $3.93 \pm 0.83$ & $22.51 \pm 4.10$ & $1.03 \pm 0.22$ \\
apoE $^{-/-}(\mathbf{H F D})+$ DIZE & $30.57 \pm 2.97$ & $5.15 \pm 0.47^{*}$ & $24.90 \pm 2.81$ & $1.04 \pm 0.14$ \\
\hline
\end{tabular}

Figure 2. Impact of DIZE on the stability of atherosclerotic plaques. Immunohistochemical staining of aortic roots showing CD68-positive macrophages $(\mathbf{A}, \mathbf{B})$ and smooth muscle $\alpha$-actin (SMA) $(\mathbf{D}, \mathbf{E})$ in control and DIZE-treated mice. Quantitative analysis of the atherosclerotic lesions area occupied by CD68-positive macrophages $(\mathbf{C})$ and smooth muscle cells $(\mathbf{F})$. The plasma levels of total cholesterol, high-density lipoproteins (HDL), low-density lipoproteins (LDL), and triglycerides (TG) $(\mathrm{G})$ in control and DIZE-treated mice. Data are mean \pm SEM analyzed using $t$-test $\left({ }^{*} p<0.05\right.$ as compared to control mice; $n=4$ or 6 per group).

\subsection{Influence of DIZE on Mesenteric Arteries Responses Ex Vivo}

We also checked the effect of DIZE on mesenteric arteries from intestine. There was no difference between DIZE-treated mice and controls regarding contraction of mesenteric arteries induced by phenylephrine (Figure 4A). Similarly, relaxations to endotheliumindependent vasodilator DEA-NO did not differ between groups (Figure 4C). However, DIZE slightly increased maximal dilatation induced by acetylcholine at the highest concentrations of Ach (Figure 4B). Besides, Ang II induced two-phase response: contractions at lower concentration and relaxation at higher, but those differences were not significant between DIZE and the control group. $\mathrm{KCl}$ only at lowest doses of $30 \mathrm{mM}$ induced less contraction in arteries of mice from DIZE group, but those differences declined at higher concentrations. Moreover, EC50 did not change significantly between groups. 

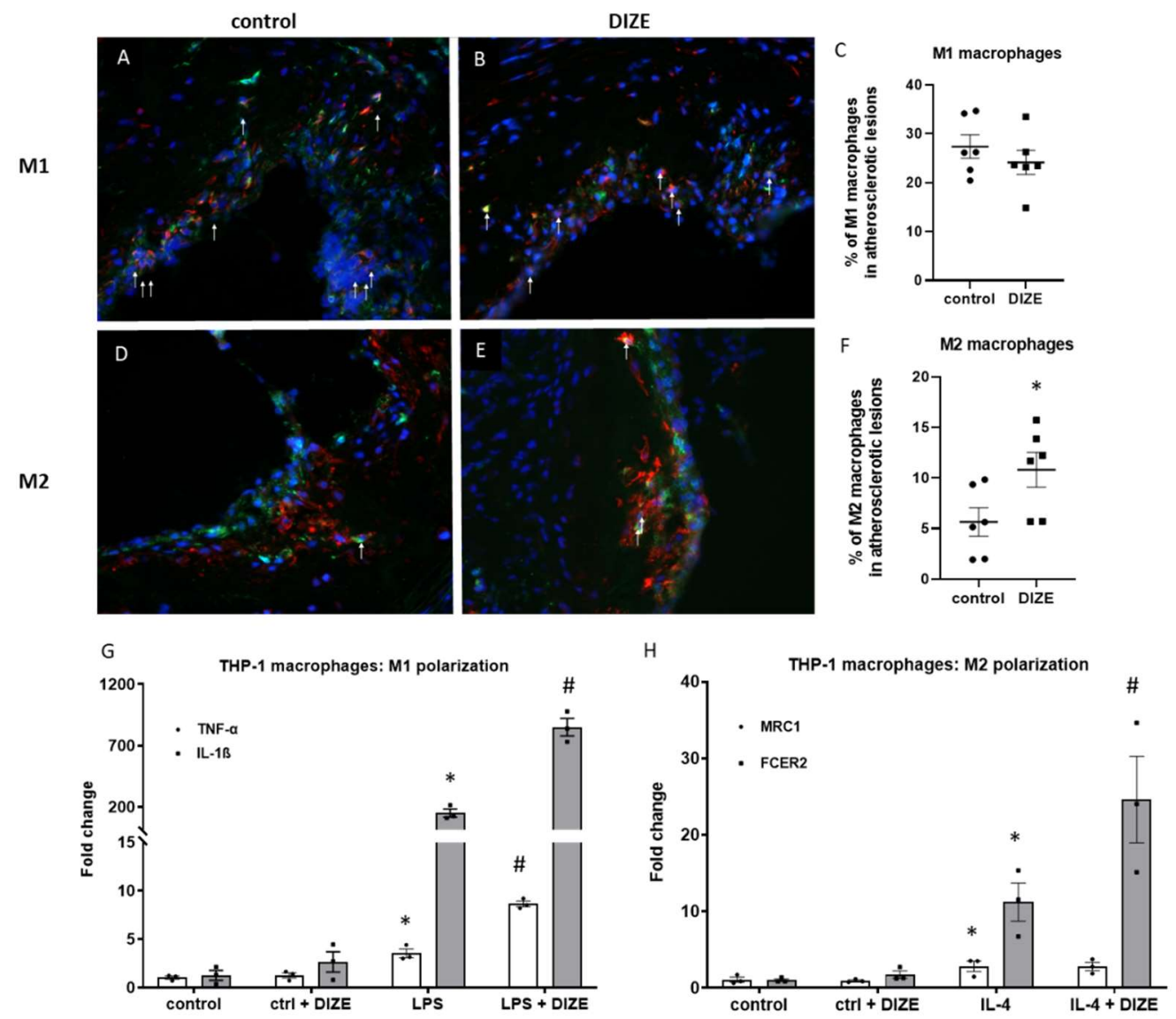

Figure 3. Macrophages polarization in atherosclerotic lesions and THP-1 cell culture after treatment with DIZE. Representative immunohistochemical staining of aortic roots showing F4/80 (green), nitric oxide synthase 2 (iNOS)/arginase 1 (red), and 4'6-diamidino-2-phenylindole (DAPI) (blue) co-localization in control (A,D) and DIZE-treated mice (B,E). White arrows indicate M1 (A,B) and M2 (D,E) macrophages, respectively. Quantitative analysis of M1 and M2 contents in the atherosclerotic plaques (C,F). mRNA expression of M1 (IL-1 $\beta$ and TNF- $\alpha)(\mathbf{G})$ and M2 (MRC1, FCER2) (H) markers in THP-1 macrophages cell culture polarized to proinflammatory M1 and anti-inflammatory M2 phenotype after treatment with DIZE. Data are mean \pm SEM analyzed using $t$-test $(\mathbf{C}, \mathbf{F})$ or one-way ANOVA with multiple comparisons and Benjamini and Hochberg false discovery rate (FDR) correction $(\mathbf{G}, \mathbf{H})\left({ }^{*} p<0.05\right.$ as compared to control; ${ }^{\#} p<0.05$ as compared to LPS or IL-4, respectively; $n=3$ independent experiments or $n=6$ biological replicates per group).

\subsection{Influence of DIZE on Hepatic Steatosis}

To evaluate the impact of DIZE on the development of hepatic steatosis in the liver of $\mathrm{apoE}^{-/-}$mice, we used hematoxylin/eosin (HE) staining. The cytoplasm of hepatocytes had a granular structure with signs of macrovesicular steatosis of about $28 \%$ of hepatocytes present in all three lobular zones, and treatment with DIZE reduced it to about $5 \%$ of hepatocytes, mostly in the first zone (Figure 5A,B,D). Furthermore, DIZE administration resulted in the significant decrease in level of triglycerides by about $33 \%$ in the liver, but not in the plasma of apoE $\mathrm{E}^{-/-}$mice (Figures $2 \mathrm{G}$ and $5 \mathrm{E}$ ). However, it increased the content of high-density lipoproteins (HDL) in the plasma of apoE ${ }^{-/-}$mice (Figure 2G). In addition, DIZE treatment lowered plasma level of the one of the markers of liver damage: alanine aminotransferase (ALT) (Figure 5F). It seems that DIZE action was associated with increased mRNA expression of NEP enzyme and tended to augment mRNA expression of ACE2 in the liver of apoE ${ }^{-/-}$mice (Figure 5C). 


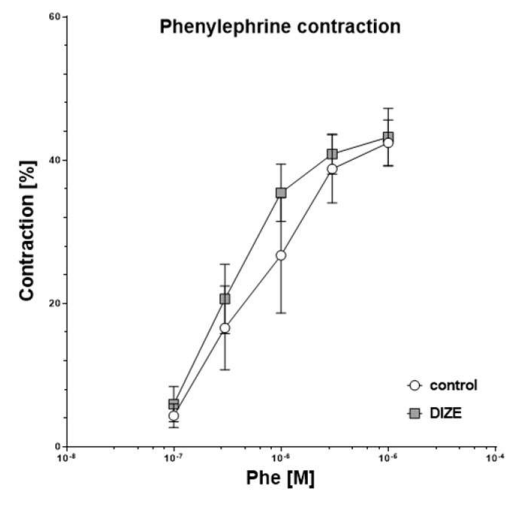

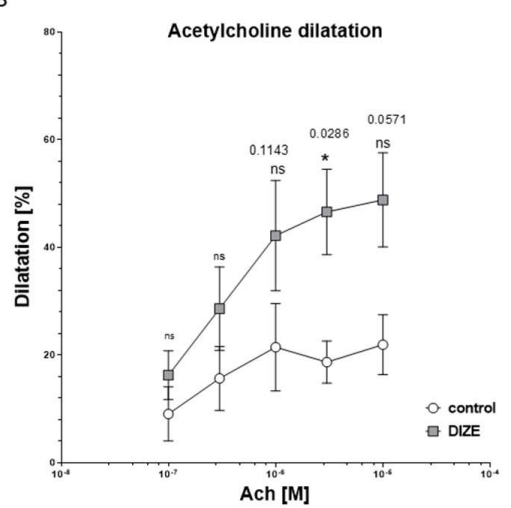

C

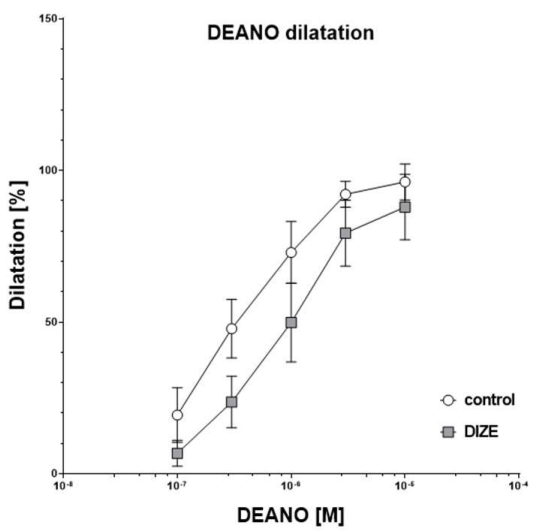

Figure 4. Graphs showing the time course response of mesenteric arteries to phenylephrine (A), acetylcholine (B), and DEA-NO (C) from control and DIZE-treated mice. Data are mean \pm SEM analyzed using nonparametric Mann-Whitney $\mathrm{U}$ test $\left({ }^{*} p<0.05\right.$ as compared to control mice; $n=4-6$ per group).
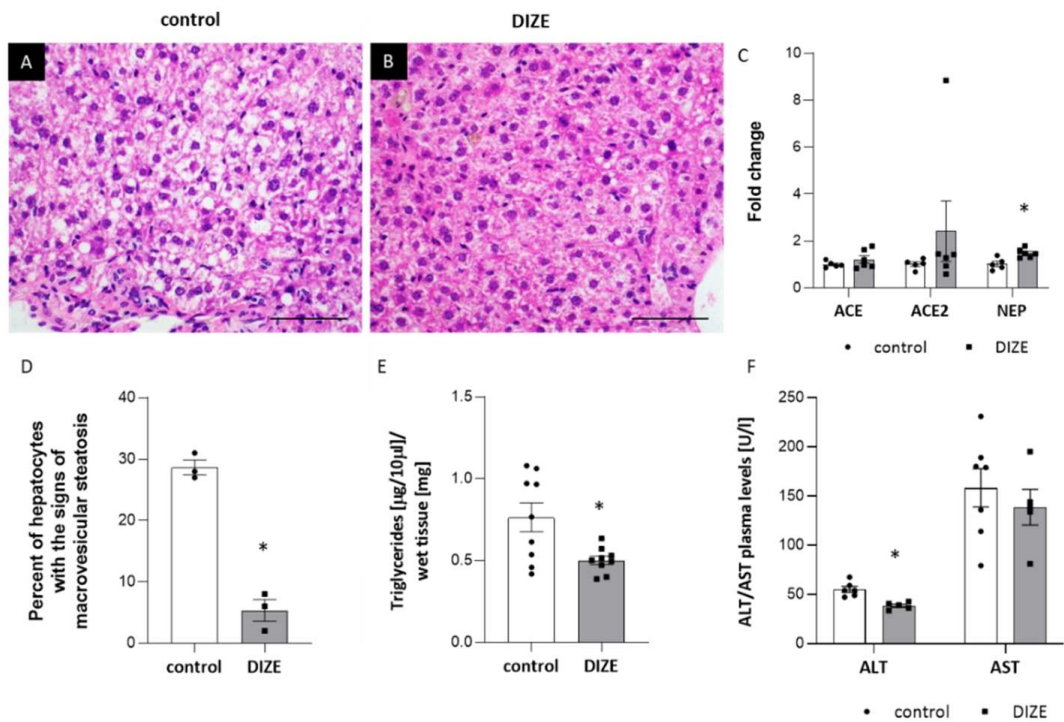

Figure 5. Influence of DIZE on the development of hepatic steatosis. Representative images of livers in control (A) and DIZE-treated mice (B). The figures show hematoxilin and eosin staining (A,B) and quantitative analysis of macrovesicular steatosis (D), triglycerides content in the liver (E) as well as plasma ALT / AST levels (F) in control and DIZE-treated mice. mRNA expression of ACE, ACE2 and NEP in the liver of control and DIZE-treated mice (C) Magnification 40x. Data are mean \pm SEM analyzed by using $t$-test ${ }^{*} p<0.05$ as compared to control mice; $n=3-9$ per group). 


\subsection{Influence of DIZE on Proteomic Changes in the Liver}

To further explore the beneficial effect of DIZE administration on the reduction in hepatic steatosis in apoE $\mathrm{E}^{-/-}$mice, we used proteomic methods. Isobaric tag for relative quantitation (iTRAQ method) combined with the multiple enzyme digestion filter aided by a sample preparation method (MED FASP) and LC-MS analysis discovered 49 differentially expressed proteins in the liver of apoE ${ }^{-/-}$mice after treatment with DIZE (Table 1). The results were presented as either volcano plot based on $\log _{2}$ fold change and $p$-value (Figure 6A) or heat map, which shows the most differentially expressed proteins in the liver of DIZE-treated apoE ${ }^{-/-}$mice (Figure $6 \mathrm{C}$ ). The most upregulated proteins were chitinaselike protein 4 (Ym2, fold change 3.36) and cysteine sulfinic acid decarboxylase (CSAD, fold change 1.45). The increased expression of CSAD in the liver of DIZE-treated apoE ${ }^{-/-}$ was also confirmed by Western blot (Figure 6B). As CSAD is an enzyme participating in taurine biosynthesis, we checked the level of taurine in the liver of apoE $\mathrm{E}^{-/-}$mice as well. Indeed, DIZE-treated apoE ${ }^{-/-}$mice had higher concentration of taurine in the liver in comparison to control mice (Figure 6B). In addition, DIZE administration led to the decreased expression of protein related to urea cycle: ornithine carbamoyltransferase, carbamoyl-phosphate synthase, arginase-1, aspartate aminotransferase, argininosuccinate synthase, ornithine aminotransferase as well as increased expression of different subunits of glutathione S-transferase (P 1, Mu 7, Mu 3, Mu 1) (Figure 6D) in the liver of apoE ${ }^{-/-}$mice.
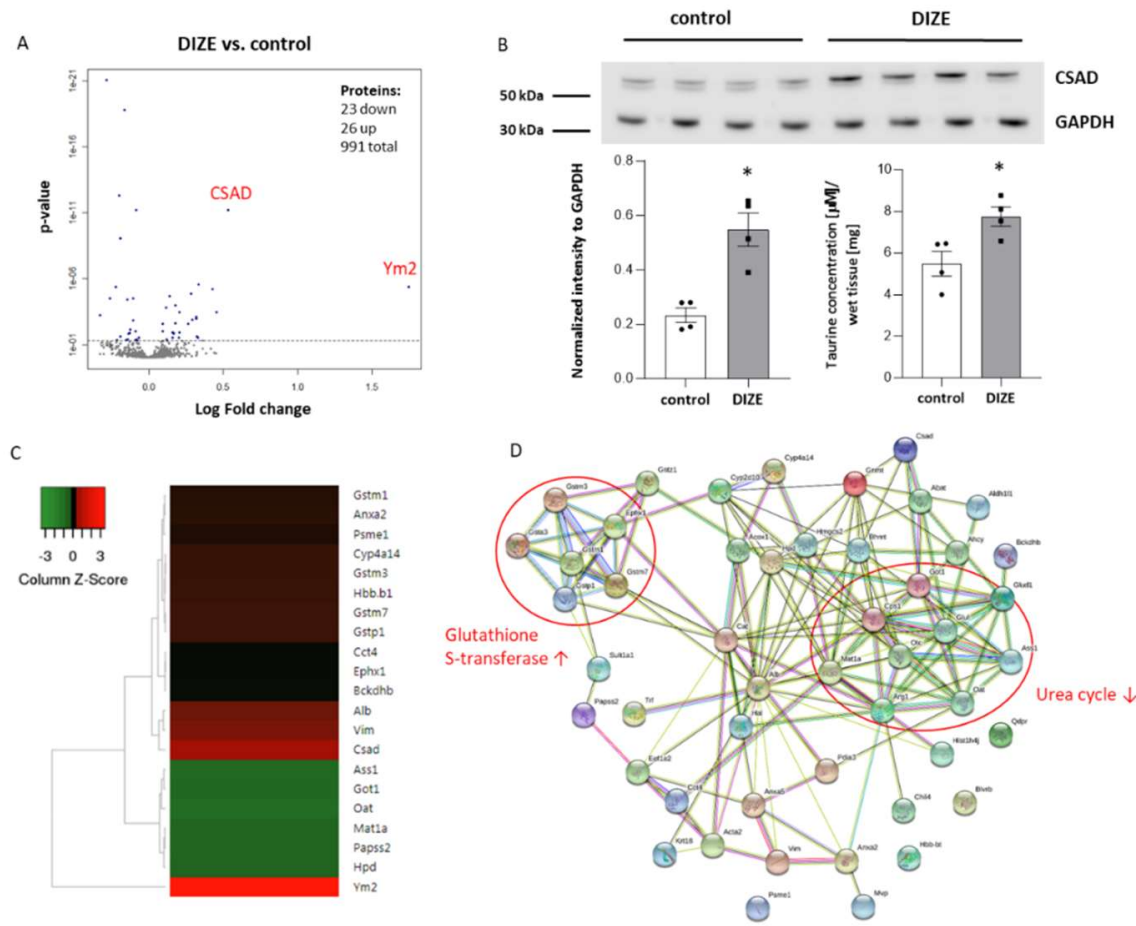

Figure 6. Proteomic analysis in the liver of DIZE-treated mice. The volcano plot of differentially expressed proteins showing the log2 fold change of protein expression vs. $p$-value in DIZE group compared to control mice (A). Validation of cysteine sulfinic acid decarboxylase (CSAD) expression by Western blot as well as the taurine levels in the liver of DIZE-treated mice (B). Heat map presentation of a hierarchical cluster of significantly changed proteins in the liver of DIZE-treated mice (C) (fold change $>1.15$ and $<-1.15$ ). Bioinformatic analysis by STRING of differentially expressed proteins reveals decreased expression of urea cycle proteins and increased expression of different isoforms of glutathione S-transferase (D). Data are mean \pm SEM analyzed using $t$-test $(\mathbf{B})$ or one-way ANOVA with Benjamini and Hochberg false discovery rate (FDR) correction $(\mathbf{A}, \mathbf{C}){ }^{*} p<0.05$ as compared to control mice; $n=4$ per group). 
Table 1. Differentially expressed proteins in the liver of $\mathrm{apoE}^{-/-}$mice treated with DIZE as compared to the control group $(p<0.05, n=4$ per group).

\begin{tabular}{|c|c|c|c|}
\hline UniProtKB ID. & Gene Name & Protein Name & Fold Change \\
\hline Q91Z98 & Chil4/Ym2 & Chitinase-like protein 4 & 3.36 \\
\hline Q9DBE0 & Csad & Cysteine sulfinic acid decarboxylase & 1.45 \\
\hline P20152 & Vim & Vimentin & 1.37 \\
\hline P07724 & $\mathrm{Alb}$ & Serum albumin & 1.35 \\
\hline P19157 & Gstp1 & Glutathione S-transferase P 1 & 1.26 \\
\hline Q80W21 & Gstm7 & Glutathione S-transferase $\mathrm{Mu} 7$ & 1.26 \\
\hline P02088 & $\mathrm{Hbb}-\mathrm{b} 1$ & Hemoglobin subunit beta-1 & 1.25 \\
\hline P19639 & Gstm3 & Glutathione S-transferase $\mathrm{Mu} 3$ & 1.25 \\
\hline O35728 & Cyp4a14 & Cytochrome P450 4A14 & 1.25 \\
\hline P07356 & Anxa2 & Annexin A2 & 1.22 \\
\hline P10649 & Gstm1 & Glutathione S-transferase Mu 1 & 1.22 \\
\hline P97371 & Psme1 & Proteasome activator complex subunit 1 & 1.20 \\
\hline Q9D379 & Ephx1 & Epoxide hydrolase 1 & 1.15 \\
\hline P80315 & Cct4 & T-complex protein 1 subunit delta & 1.15 \\
\hline Q6P3A8 & Bckdhb & 2-oxoisovalerate dehydrogenase subunit beta, mitochondrial & 1.15 \\
\hline P48036 & Anxa5 & Annexin A5 & 1.13 \\
\hline Q921I1 & Tf & Serotransferrin & 1.13 \\
\hline Q923D2 & Blvrb & Flavin reductase (NADPH) & 1.12 \\
\hline P24456 & Cyp2d10 & Cytochrome P450 2D10 & 1.12 \\
\hline Q9EQK5 & Mvp & Major vault protein & 1.12 \\
\hline P62806 & Hist1h4a & Histone $\mathrm{H} 4$ & 1.12 \\
\hline P62737 & Acta2 & Actin, aortic smooth muscle & 1.10 \\
\hline P15105 & Glul & Glutamine synthetase & 1.09 \\
\hline P54869 & Hmgcs2 & Hydroxymethylglutaryl-CoA synthase, mitochondrial & 1.09 \\
\hline P27773 & Pdia3 & Protein disulfide-isomerase A3 & 1.07 \\
\hline P26443 & Glud1 & Glutamate dehydrogenase 1, mitochondrial & 1.07 \\
\hline P11725 & Otc & Ornithine carbamoyltransferase, mitochondrial & -1.04 \\
\hline Q9R0H0 & Acox1 & Peroxisomal acyl-coenzyme A oxidase 1 & -1.06 \\
\hline P05784 & Krt18 & Keratin, type I cytoskeletal 18 & -1.06 \\
\hline Q8C196 & Cps1 & Carbamoyl-phosphate synthase [ammonia], mitochondrial & -1.06 \\
\hline P24270 & Cat & Catalase & -1.06 \\
\hline Q9WVL0 & Gstz1 & Maleylacetoacetate isomerase & -1.06 \\
\hline Q61176 & Arg1 & Arginase- 1 & -1.07 \\
\hline P50247 & Ahcy & Adenosylhomocysteinase & -1.08 \\
\hline P30115 & Gsta3 & Glutathione S-transferase A3 & -1.09 \\
\hline Q8BVI4 & Qdpr & Dihydropteridine reductase & -1.09 \\
\hline P61922 & Abat & 4-aminobutyrate aminotransferase, mitochondrial & -1.10 \\
\hline P35492 & Hal & Histidine ammonia-lyase & -1.10 \\
\hline Q9QXF8 & Gnmt & Glycine N-methyltransferase & -1.10 \\
\hline P52840 & Sult1a1 & Sulfotransferase $1 \mathrm{~A} 1$ & -1.11 \\
\hline Q8R0Y6 & Aldh111 & Cytosolic 10-formyltetrahydrofolate dehydrogenase & -1.12 \\
\hline P62631 & Eef1a2 & Elongation factor 1-alpha 2 & -1.14 \\
\hline O35490 & Bhmt & Betaine-homocysteine S-methyltransferase 1 & -1.14 \\
\hline P49429 & Hpd & 4-hydroxyphenylpyruvate dioxygenase & -1.15 \\
\hline O88428 & Papss2 & Bifunctional 3'-phosphoadenosine $5^{\prime}$-phosphosulfate synthase 2 & -1.16 \\
\hline Q91X83 & Mat1a & S-adenosylmethionine synthase isoform type-1 & -1.17 \\
\hline P05201 & Got1 & Aspartate aminotransferase, cytoplasmic & -1.20 \\
\hline P16460 & Ass1 & Argininosuccinate synthase & -1.22 \\
\hline P29758 & Oat & Ornithine aminotransferase, mitochondrial & -1.25 \\
\hline
\end{tabular}

\section{Discussion}

The renin-angiotensin system (RAS) with its two main opposing effectors: Ang II and Ang-(1-7) is widely recognized as a major regulator of cardiovascular function and body metabolic processes [8,9]. ACE2 by breaking-down Ang II forms Ang-(1-7) and thus favors Ang-(1-7) actions. In the present study, we found that ACE2 activator, diminazene 
aceturate (DIZE), stabilized atherosclerotic plaque and attenuated hepatic steatosis in $\mathrm{apoE}^{-/-}$mice by influencing macrophages polarization and taurine biosynthesis.

ACE2/Ang-(1-7)/Mas axis has been shown to elicit atheroprotective effects [14]. Genetic knockdown of ACE2 worsened atherosclerosis in apoE $\mathrm{E}^{-/-}$and low-density lipoprotein receptor ( $\mathrm{Ldlr}^{-/-}$) knockout mice and consistently, its overexpression attenuated atherosclerosis and enhanced atherosclerotic plaque stability $[16,17,24]$. Interestingly, our results indicate that even prolonged administration of DIZE mixed with an HFD diet at a dose of $30 \mathrm{mg} / \mathrm{kg} /$ day for 16 weeks did not reduce atherosclerotic lesions and necrotic core in apoE $\mathrm{E}^{-/-}$mice. It is in line with other study showing that shorter treatment with DIZE at a lower dose of $15 \mathrm{mg} / \mathrm{kg} /$ day for 3 weeks did not attenuate atherogenesis but stabilized atherosclerotic lesions in a shear stress-induced model of vulnerable atherosclerotic plaque in apo $E^{-/-}$mice [25]. Indeed, our results also point out stabilization of atherosclerotic lesions after prolonged DIZE treatment: decreased macrophages content as evidenced by CD68 staining and increased smooth muscle $\alpha$-actin (SMA) content. This is consistent with the previous studies showing stabilized atherosclerotic lesions in animal models of either overexpressed ACE2 or pharmacologically activated ACE2, with reduced inflammatory cells infiltration as well as MMP-9 and MMP-3 levels, and increased collagen content $[16,25]$.

To more deeply explore the composition of atherosclerotic plaques after DIZE administration, we also checked the content of proinflammatory M1 and anti-inflammatory M2 phenotypes of macrophages. Interestingly, DIZE treatment elevated the level of M2 macrophages but did not change the level of M1 macrophages in atherosclerotic lesions of $\mathrm{apoE}^{-/-}$mice, which might further indicate more stabilized atherosclerotic plaques after prolonged DIZE administration. Tissue-resident macrophages elicit vast plasticity and can be classified according to two main phenotypes: proinflammatory M1 macrophages, characterized by production of nitric oxide (NO) and inflammatory cytokines (IL-1 $\beta$ and TNF- $\alpha$ ) and being responsible for the clearance of pathogens, and anti-inflammatory M2 macrophages, which release an anti-inflammatory cytokine IL-10 and play a role in resolution of inflammation, tissue repair, and wound healing [26,27]. Importantly, it has been shown that macrophage phenotype may have impact on plaque vulnerability in atherosclerosis. More M1 macrophages were observed in unstable plaque and more M2 macrophages were seen in stable plaque in patients with acute ischemic attack [28]. In addition, several studies have demonstrated that M1 macrophage phenotype is linked to atherosclerosis progression $[29,30]$ and, in turn, the induction of macrophage polarization to M2 by IL-13 could reduce disease progression [31]. Therefore, the macrophage class switching to M2 phenotype induced by DIZE could be a potential therapeutic approach in the treatment of atherosclerosis.

Moreover, we confirmed macrophage polarization results in vitro using a cell line model: THP-1 macrophages polarized to M1 and M2 in the presence of DIZE. In fact, DIZE administration increased level of anti-inflammatory M2 marker (FCER2) in THP-1 macrophages differentiated to M2 phenotype. Surprisingly, however, it also elevated gene expression of proinflammatory M1 markers (IL-1 $\beta$ and TNF- $\alpha$ ) in THP-1 macrophages polarized to M1. Discrepancies between in vivo and in vitro results of M1 macrophage levels after DIZE treatment might be due to the presence and the role of membrane bound ACE2 vs. soluble circulating form of ACE2, which is a proteolytic product of shedding of membrane-bound ACE2 by disintegrin and metalloproteinase domain-containing protein 17 (ADAM17) [32]. Nevertheless, our results are in contrast with other study showing that DIZE suppressed the production of proinflammatory cytokines: IL-6, TNF- $\alpha$, and IL-12 in bone marrow-derived macrophages (BMDM) and mice challenged with LPS [33]. Further research is needed to clarify the impact of ACE2 activator, DIZE, on proinflammatory macrophages, especially nowadays, as ACE2 is recognized as both binding receptor for severe acute respiratory syndrome coronavirus 2 (SARS-CoV-2) and important factor limiting lung injury in coronavirus disease-19 (COVID-19) caused by SARS-CoV-2. Only recently, DIZE has been proposed as a potential drug to prevent SARS-CoV-2 complications [34]. 
A growing body of evidence indicates that NAFLD is an important independent risk factor for the development of atherosclerosis [5]. ACE2/Ang-(1-7)/Mas axis has been reported to contribute to the development of NAFLD [15]. In this study, we showed that ACE2 activator, DIZE, attenuated hepatic steatosis in $\mathrm{apoE}^{-/-}$mice along with the reduction in triglycerides content in the liver and upregulation of HDL level in the plasma. In addition, DIZE improved liver function by decreasing the level of alanine aminotransferase (ALT). Our results are in line with other studies showing that genetic knockdown of ACE2 in mice aggravated hepatic steatosis, oxidative stress, and inflammation by activating Akt signaling [18]. In turn, oral administration of Ang-(1-7) prevented hepatic steatosis, improved metabolism, and decreased inflammation in mice [35]. Moreover, transgenic rats overexpressing Ang-(1-7) had lowered level of triglycerides in the liver [36].

To elucidate the mechanism of action of DIZE in the liver of apoE ${ }^{-/-}$mice, we applied proteomic method: iTRAQ combined with the multiple enzyme digestion filter aided by a sample preparation method (MED FASP) and LC-MS analysis. Among 49 differentially expressed proteins, two proteins with the highest upregulation level after DIZE treatment: chitinase-like protein 4 (Ym2) and cysteine sulfinic acid decarboxylase (CSAD) are worth further discussion. Ym2 belongs to the glycoside hydrolase family 18 of proteins that are responsible of chitin degradation and act as host-defense enzymes. Little is known about $\mathrm{Ym} 2$ function, as this protein is less abundant, was not widely studied and has high sequence similarity ( 95\%) to Ym1 [37]. Ym1 is considered as an M2 marker in mouse and may play a role in inflammatory responses and allergy [38]. However, whether DIZE not only increases the content of M2 macrophages in the atherosclerotic lesions but also in the liver requires further investigations. In turn, CSAD is an enzyme participating in taurine biosynthesis, which converts cysteine sulfinic acid to hypotaurine and $\mathrm{CO}_{2}$. Our proteomics results showed increased expression of CSAD in the liver of DIZE-treated apoE ${ }^{-/-}$mice, which was additionally confirmed by Western blot. Consistently, we also observed elevated taurine concentration in the liver of apoE $\mathrm{E}^{-/-}$mice after DIZE administration. Taurine is one of the most abundant amino acids in mammals and basic regulator of biological and physiological processes. It has been shown that taurine could prevent atherogenesis in mice and rabbits by influencing osmoregulation, oxidation, and inflammation [39] as well as could attenuate hepatic steatosis in mice on an HFD through the inhibition of oxidative stress [40]. Interestingly, taurine has been also reported to modulate the phenotype of macrophages towards increasing M2 macrophages in adipose tissues, which was measured by elevated gene expression of M2 markers: Ym1, Arg1, and MGL1 [41]. Thus, increased biosynthesis and concentration of taurine in the liver of apoE $\mathrm{E}^{-/-}$mice treated with DIZE might be presumably one of the beneficial mechanisms of DIZE action in the reduction in hepatic steatosis and stabilization of atherosclerotic plaques.

In our setting, the use of DIZE did not change the response of the mesenteric arteries to phenylephrine and the NO donor (DEA-NO) but increased the endothelial-dependent relaxation induced by acetylcholine. The mechanism of such effect could depend on an increase in endothelial eNOS-derived NO release and/or improvement of NO bioavailability. Interestingly, DIZE has recently been shown to increase NO production in the mesenteric artery of SHR-treated rats, but the mechanism of this action has not been thoroughly characterized [42]. Intriguingly, recently NO secretion-enhancing effect of taurine has been described [43]. Several possible mechanisms of such action of taurine have been proposed, i.e., increasing eNOS expression, eNOS phosphorylation on Ser1177, NO bioavailability, the level of antioxidative defense, and the influence on L-arginine/NOS inhibitor asymmetric dimethylarginine (ADMA) ratio, however, whether and which of them may be involved in the action of DIZE in our experimental model requires further research.

Our research has several strengths: we investigated a compound with a low, wellestablished toxicity that is well suited to repurposing and new use. We also pointed out new, interesting mechanisms of the drug's action that may be responsible for the stabilization of atherosclerotic plaque and the reduction in fatty liver. It is tempting to speculate that ACE2 activator, DIZE, provides potentially a novel therapeutic approach 
to the treatment/prevention of atherosclerosis and fatty liver diseases by influencing macrophages polarization and taurine biosynthesis. However, the exact understanding of mechanisms of the advantageous actions of DIZE require further studies.

Nevertheless, our study has several limitations. DIZE is mainly recognized as an antitrypanosomal drug and ACE2 activator, but it also elicits other pharmacological properties. It can inhibit acid-sensitive ion channels ( $\mathrm{ASIC}_{1 \mathrm{a}}, \mathrm{ASIC}_{1 \mathrm{~b}}, \mathrm{ASIC}_{2 \mathrm{a}}$, and $\mathrm{ASIC}_{3}$ ), which play a role in the perception of $\mathrm{pH}$ changes during extracellular tissue acidosis [44]. Additionally, some studies showed contradictory results regarding the ability of DIZE to activate ACE2 $[45,46]$. However, apart from the activation of ACE2, DIZE might also increase the mRNA/protein expression of ACE2, which we also observed in our setting [20]. Further studies should be done to evaluate whether DIZE-induced elevated ACE2 activity occurs directly or indirectly as a result of increased mRNA expression.

\section{Materials and Methods}

\subsection{Animal Studies}

Twenty-two female apolipoprotein E-knockout mice on the C57BL/6J background were obtained from Taconic (Ejby, Denmark). The animals were maintained on $12 \mathrm{~h}$ dark $/ 12 \mathrm{~h}$ light cycles at room temperature $\left(22.5 \pm 0.5^{\circ} \mathrm{C}\right)$ and at $45-55 \%$ humidity with access to water ad libitum and diet. At the age of 8 weeks, the mice were fed with a high-fat diet (HFD) (containing $15.2 \%$ fat and $0.25 \%$ cholesterol) for 16 weeks. The diet was prepared by Morawski (Kcynia, Poland). The animals were divided into two groups: female apoE ${ }^{-/-}$mice on high-fat diet (control) $(n=11)$ and female apoE ${ }^{-/-}$mice on an HFD treated with diminazene aceturate (DIZE) $(n=11)$. DIZE was mixed without heating with the HFD and administered to the mice at a dose of $30 \mathrm{mg}$ per $\mathrm{kg}$ of body weight per day. The dose of DIZE was chosen based on the previous results from mice studies [25,47]. At the age of 6 months, the mice were euthanized 5 min after injection of Fraxiparine (Nadroparin) i.p. (1000 UI; Sanofi-Synthelabo, Paris, France) in chamber filled with carbon dioxide at a rate of $20-30 \% \mathrm{CO}_{2}$ chamber volume per minute, in accordance with AVMA Panel 2007 recommendations and institutional IACUC guidelines. The selected tissues (aortas, hearts, livers, and intestine together with mesenteric arteries) were dissected and the blood was collected. All animal procedures were conformed with the guidelines from Directive 2010/63/EU of the European Parliament on the protection of animals used for scientific purposes and were approved by the Jagiellonian University Ethical Committee on Animal Experiments (no. 67/2014).

\subsection{Atherosclerotic Lesion Assessment}

The development of atherosclerotic lesions in $\mathrm{apoE}^{-/-}$mice was evaluated using cross-section method, as described before [48]. The aortic sections (10- $\mu \mathrm{m}$ thickness) were stained with Oil Red-O (Sigma-Aldrich, St. Louis, MO, USA) to measure the area of atherosclerotic plaques. The necrotic core of atherosclerotic lesions in apoE $\mathrm{E}^{-/-}$mice was assessed by the hematoxylin-eosin (HE) staining. Aortic images were captured using Olympus BX50 (Olympus, Tokyo, Japan) microscope, and the data were analyzed by the LSM Image Browser software (Zeiss, Jena, Germany).

\subsection{Immunohistochemical Staining of Aortic Roots}

Sections of ascending aorta were fixed in acetone and used for immunohistochemistry, as described previously [48]. To detect the content of macrophages and smooth muscles cells in atherosclerotic plaques, the sections were stained with primary antibodies against CD68 (Serotec, Kidlington, UK) (dilution 1:800) and smooth muscle $\alpha$-actin (SMA) (SigmaAldrich, St. Louis, MO, USA) (dilution 1:800), respectively. Macrophage polarization was assessed as described before [49]. Antibodies were used against F4/80 (Abcam, Cambridge, UK) (dilution 1:100), nitric oxide synthase 2 (iNOS) (Abcam, Cambridge, UK) (dilution 1:200), arginase 1 (Abcam, Cambridge, UK) (dilution 1:100), and 4'6-diamidino-2phenylindole (DAPI), for total macrophages, M1-like, M2-like, and cell nuclei, respectively. 
The images were recorded using the Camedia DP71 digital camera (Olympus, Tokyo, Japan). The analysis of all sections was performed using the LSM Image Browser software (Zeiss, Jena, Germany).

\subsection{Histology of the Liver}

The samples of the liver tissues were fixed using formalin and embedded in paraffin. The paraffin sections ( $2 \mu \mathrm{m}$ thickness) were stained with hematoxylin-eosin (HE) method, as previously described [50].

\subsection{Biochemical Measurement}

The blood was centrifuged at $1000 \times g$ at $4{ }^{\circ} \mathrm{C}$ for $10 \mathrm{~min}$, and then the plasma was collected and stored at $-80^{\circ} \mathrm{C}$. The levels of total cholesterol, TG, LDL, and HDL in the plasma were measured using commercially available kits (Roche Molecular Biochemical, Pleasanton, CA, USA). In addition, levels of aspartate aminotransferase (AST) and alanine aminotransferase (ALT) were measured by the Reflovet Plus equipment (Roche, Basel, Switzerland) using commercial kits: Reflotron GOT, Reflotron GPT (Roche, Basel, Switzerland). Moreover, the Taurine Assay Kit (Cell Biolabs, San Diego, CA, USA) was used to determine the concentration of taurine in the liver. The content of TG in the liver was assayed using the Triglyceride Colorimetric Assay Kit (Cayman Chemical, Ann Arbor, MI, USA), according to the manufacturer's guidelines.

\subsection{Western Blot Analysis}

Immunoblotting analysis used to determine the expression of CSAD was conducted as previously described [50]. Briefly, the samples were separated on SDS-polyacrylamide gels (7.5-15\%) (Mini Protean II, Bio-Rad, Hercules, CA, USA) using the Laemmli buffer system and semidry transferred to nitrocellulose membranes (GE Healthcare, Chicago, IL, USA). The membranes were blocked overnight at $4{ }^{\circ} \mathrm{C}$ with $5 \%(w / v)$ non-fat dried milk in TTBS and incubated for $3 \mathrm{~h}$ at room temperature with specific primary antibodies followed by $1 \mathrm{~h}$ incubation with HRP-conjugated secondary antibodies (GE Healthcare, Chicago, IL, USA). Bands were developed with the use of ECL-system reagents (GE Healthcare, Chicago, IL, USA). GAPDH was used as a control of equal protein content. The following specific primary antibodies were applied: ANTI-CSAD (MyBioSource, San Diego, CA, USA) and ANTI-GAPDH (MyBioSource, San Diego, CA, USA). The images were visualized using the ImageQuant Las 500 (GE Healthcare, Chicago, IL, USA) and analyzed by Image Lite Studio software (LI-COR, Lincoln, NE, USA).

\subsection{Real-time PCR}

Real-time PCR technique was used to determine the expression levels of ACE, ACE2, and NEP genes in the aorta and the liver of $\mathrm{apoE}^{-/-}$mice, and IL- $1 \beta$, TNF- $\alpha$, MRC1, and FCER2 genes in THP-1 macrophages according to protocol, as described previously [50]. Briefly, RNA was isolated using the RNeasy Fibrous Tissue Mini Kit (Qiagen, Hilden, Germany) and transcribed to cDNA with the High-Capacity cDNA Reverse Transcription Kit (Thermo Scientific, Waltham, MA, USA). Commercially available primers from Bio-Rad (Hercules, CA, USA) (IL-1 $\beta$, TNF- $\alpha$, MRC1, FCER2, and GAPDH) and Qiagen (Hilden, Germany) (ACE, ACE2, NEP) and GoTaq ${ }^{\circledR}$ qPCR Master Mix (Promega, Madison, WI, USA) were used to carry out the real-time PCR reaction. Analysis of relative gene expression with GAPDH as an internal reference gene was performed by the 7900HT fast real-rime PCR System (Applied Biosystems, Foster City, CA, USA), and the data were analyzed using the $2^{-\Delta \Delta C t}$ method by Data Assist v3.01 software (Applied Biosystems, Foster City, CA, USA).

\subsection{Mesenteric Arteries Preparation}

Segment of intestine together with mesenteric arteries was quickly excised from mice and placed in cold saline solution. The segment of first- or second-order branch of the superior mesenteric artery was cleared from surrounding adipose tissue and cannulated 
in the pressure myograph (JP Trading, Aarhus, Denmark). The chamber of the pressure myograph as well interior of vessel was filled with modified Krebs-Henseleit solution having following composition in $\mathrm{mM}$ : $\mathrm{NaCl} 119, \mathrm{KCl} 4.7, \mathrm{KH}_{2} \mathrm{PO}_{4} 1.18, \mathrm{MgSO}_{4} 1.17$, $\mathrm{CaCl}_{2} 2.5, \mathrm{NaHCO}_{3} 25$, glucose 5.5, pyruvate 2, and EDTA 0.5. The buffer in the chamber was bubbled with gas mixture of $21 \%$ oxygen and $5 \%$ carbon dioxide with nitrogen and temperature was set at $37^{\circ} \mathrm{C}$. The outer diameter of the vessels was continuously monitored by a video camera attached to an inverted microscope. After 30 min of stabilization at $10 \mathrm{~mm} \mathrm{Hg}$, pressure was raised to $60 \mathrm{~mm} \mathrm{Hg}$ and stabilized for another $15 \mathrm{~min}$. All drugs were applied extraluminally to the myograph chamber. The experiment protocol was as follows: after stabilization, concentration-response curve for phenylephrine (Phe) (in the range of $10^{-7}$ to $10^{-5} \mathrm{M}$ ) was obtained. After washing with Krebs-Henseleit buffer, vessel was submaximally preconstricted with Phe (usually $10^{-6} \mathrm{M}$ ), and increasing concentrations of acetylcholine (Ach) (also in the range of $10-{ }^{7} \mathrm{M}$ to $10^{-5} \mathrm{M}$ ) were applied. Next, similar concentration-response curve for DEA-NO was obtained. Then, after washing, but without preconstriction with Phe, increasing doses (in the range of $10^{-9}$ to $10^{-6} \mathrm{M}$ ) of angiotensin II were applied. Last substance tested was $\mathrm{KCl}$ in the concentration range of 30-90 mM. Finally, passive diameter was measured after incubating vessel in calcium-free Krebs-Henseleit buffer. The relaxation response was expressed as a percentage of the pre-contraction induced by phenylephrine, and the EC50 values for individual vessels were calculated.

\subsection{Proteomics Studies in the Liver}

Liver samples from apoE $\mathrm{E}^{-/-}$mice and $\mathrm{apoE}^{-/-}$mice treated with DIZE $(n=4$ per group) were homogenized using a Tissue Lyser LT (Qiagen, Germany) and lysed in a buffer containing $0.1 \mathrm{M}$ Tris- $\mathrm{HCl}, \mathrm{pH} 8.0,2 \%$ sodium dodecyl sulfate, and $50 \mathrm{mM}$ dithiothreitol (Sigma Aldrich, Saint Louis, MI, USA) at $96^{\circ} \mathrm{C}$ for $10 \mathrm{~min}$. Protein concentration was measured by Pierce $660 \mathrm{~nm}$ Protein Assay Kit (Thermo Scientific, USA). Seventy micrograms of protein content were digested using the multiple enzyme digestion filter aided by a sample preparation method (MED FASP) [51,52] with two enzymes: endoproteinase LysC and trypsin. Next, samples were purified with C18 MacroSpin Columns (Harvard Apparatus, Cambridge, MA, USA) and prepared as recommended by the iTRAQ protocol (AB Sciex, Framingham, MA, USA). Four samples from each group were labeled with iTRAQ reagents as follows: control-113, 115, 117, 119 and DIZE-114, 116, 118, 121. Then, the labeled samples were combined, dried in a vacuum concentrator (Eppendorf, Hamburg, Germany), and dissolved in $0.1 \%$ trifluoroacetic acid in order to purify it with C18 MacroSpin columns (Harvard Apparatus, Cambridge, MA, USA). Eluates were reconstituted in 0.2 ammonium formate, $\mathrm{pH}$ 10.0, and subject to fractionation under high $\mathrm{pH}$ conditions (Harvard Apparatus, Cambridge, MA, USA). Peptides were eluted in 10 consecutive salt steps (15\%, $17.5 \%, 20 \%, 22.5 \%, 25 \%, 27.5 \%, 30 \%, 32.5 \%, 35 \%$, and $50 \%$ acetonitrile in $0.05 \mathrm{M}$ ammonium formate) and dried in a vacuum concentrator. The samples were dissolved in 5\% acetonitrile with $0.1 \%$ formic acid and concentrated on a trap column (Acclaim PepMap100 RP C18 $75 \mu \mathrm{m}$ i.d. $\times 2 \mathrm{~cm}$ column, Thermo Scientific Dionex, Sunnyvale, CA, USA) and then injected on-line onto a PepMap100 RP C18 $75 \mu \mathrm{m}$ i.d. $\times 15 \mathrm{~cm}$ column (Thermo Scientific Dionex, Sunnyvale, CA, USA). Peptides were separated over a $90 \mathrm{~min} 7-55 \%$ B phase linear gradient (A phase: $2 \%$ acetonitrile and $0.1 \%$ formic acid; B phase: $80 \%$ acetonitrile and $0.1 \%$ formic acid) with a flow rate of $300 \mathrm{~nL} / \mathrm{min}$ by UltiMate $3000 \mathrm{HPLC}$ system (Thermo Scientific Dionex, Sunnyvale, CA, USA) and applied on-line to a Velos Pro (Thermo Scientific, Waltham, MA, USA) dual-pressure ion-trap mass spectrometer. The nano-electrospray ion source (Nanospray Flex, Thermo Scientific, Waltham, MA, USA) parameters consisted of ion spray voltage of $1.7 \mathrm{kV}$ and capillary temperature of $250{ }^{\circ} \mathrm{C}$. The spectra were collected over a full scan mode (400-1500 Da) followed by one higher energy collisional dissociation (HCD) of the five most intense ions from the preceding survey's full scan under dynamic exclusion criteria. These spectra were analyzed by the X!Tandem (The Global Proteome Machine Organization) and Comet search algorithms and then validated with Peptide 
Prophet and iProphet under Trans-Proteomic Pipeline software (Institute for Systems Biology, Seattle, WA, USA). Search parameters consisted of several aspects: (1) taxonomy: rat (UniProtKB/Swiss-Prot); (2) enzyme: trypsin; (3) missed cleavage sites allowed: 2; (4) fixed modification: Methylthio(C); (5) variable modifications: methionine oxidation(M); (6) iTRAQ 8-plex (K), iTRAQ 8-plex (N-term), and iTRAQ 8-plex (Y); (7) parent mass error: 1.5 to + 3.0 Da; and (8) peptide fragment mass tolerance: 0.7 Da. Quantitative information was extracted with Libra software under Trans-Proteomic Pipeline. The peptide false discovery rate was estimated by Mayu (Trans-Proteomic Pipeline), and peptide identifications with false discovery rates $<1 \%$ were considered as correct matches. DanteR software was used for statistical analysis of iTRAQ-labeled peptides [53]. Briefly, the data were log2 transformed and normalized using quantile regression. Analysis of variance (ANOVA) was performed at a peptide level and the Benjamini and Hochberg false discovery rate (FDR) correction was used to adjust $p$-values. The mass spectrometry proteomic data were deposited to the ProteomeXchange Consortium via the PRIDE partner repository with the dataset identifier PXD022829.

\subsection{THP-1 Cell Culture}

Human THP-1 monocytic cell line (ATCC, Manassas, VA, USA) was grown in a humidified incubator containing $5 \% \mathrm{CO}_{2}$ and $95 \%$ air at $37{ }^{\circ} \mathrm{C}$ in RPMI 1640 medium (Gibco, MA, USA) supplemented with $10 \%$ fetal bovine serum (FBS, Gibco, MA, USA) and streptomycin $(100 \mu \mathrm{g} / \mathrm{mL}) /$ penicillin $(100 \mathrm{U} / \mathrm{mL})$. In order to differentiate THP-1 monocytes to macrophages, the cells were placed in 6-well plates $\left(1.5 \times 10^{6}\right.$ cells per well, passage 1-3) in $3 \mathrm{~mL}$ of culture medium and treated with $10 \mathrm{nM}$ phorbol 12-myristate 13-acetate (PMA; Sigma Aldrich, St. Louis, MO, USA) for $72 \mathrm{~h}$. After 3 days of resting, THP-1 macrophages were polarized for $24 \mathrm{~h}$ with $100 \mathrm{ng} / \mathrm{mL}$ LPS (Salmonella Minnesota; InvivoGen, San Diego, CA, USA) or 33 ng/mL IL-4 (R\&D Systems, Minneapolis, MN, USA) to M1 and M2 macrophages, respectively. DIZE (10 $\mu \mathrm{M}$, based on our previous results) was added $1 \mathrm{~h}$ before stimulation with LPS and IL-4. The expression of M1 and M2 markers was assessed using real-time PCR.

\subsection{Statistical Analysis}

The data were expressed as a mean + SEM. The equality of variance (F-test) and the normality of the data (Shapiro-Wilk test) were checked and based on the outcome. The statistical analysis was performed using nonparametric Mann-Whitney $\mathrm{U}$ test or $t$-test/oneway ANOVA with multiple comparisons and Benjamini and Hochberg false discovery rate (FDR) correction (GraphPad Prism 8, San Diego, CA, USA). The values of $p<0.05$ were considered statistically significant.

\section{Conclusions}

We have shown that ACE2 activator, DIZE, given orally for 16 weeks, was able to stabilize atherosclerotic lesions and attenuate hepatic steatosis in apoE ${ }^{-/-}$mice fed an HFD. Such effects were associated with decreased total macrophages content but increased anti-inflammatory M2 macrophages and $\alpha$-smooth muscle actin levels in atherosclerotic plaques. Interestingly, the anti-steatotic action of DIZE in the liver was related to the decreased levels of triglycerides in liver, elevated levels of HDL in the plasma, and increased biosynthesis and concentration of taurine. Yet, the exact molecular mechanisms of both the anti-atherosclerotic and anti-steatotic actions of DIZE require further clarifications.

Author Contributions: Conceptualization, R.O. and J.J.; formal analysis, A.S., M.S., M.B., B.B.-G., and R.O.; investigation, A.S., A.K., A.W., K.S., M.Ł., J.T.-Ż. and K.K.; writing-original draft preparation, A.S.; writing-review and editing, R.O. All authors have read and agreed to the published version of the manuscript.

Funding: This research was funded by the National Science Centre (NCN), grant number 2017/26/D/NZ4/00480. 
Institutional Review Board Statement: The study was conducted according to the guidelines of the Declaration of Helsinki and approved by the Jagiellonian University Ethical Committee on Animal Experiments (no 67/2014).

Informed Consent Statement: Not applicable.

Data Availability Statement: The mass spectrometry proteomic data were deposited to the ProteomeXchange Consortium via the PRIDE partner repository with the dataset identifier PXD022829.

Conflicts of Interest: The authors declare no conflict of interest.

$\begin{array}{ll}\text { Abbreviations } \\ \text { ACE } & \text { angiotensin-converting enzyme } \\ \text { ACE2 } & \text { angiotensin-converting enzyme 2 } \\ \text { ALT } & \text { alanine aminotransferase } \\ \text { AST } & \text { aspartate aminotransferase } \\ \text { CSAD } & \text { cysteine sulfinic acid decarboxylase } \\ \text { DIZE } & \text { diminazene aceturate } \\ \text { HDL } & \text { High-density lipoprotein } \\ \text { HE } & \text { hematoxylin/eosin } \\ \text { HFD } & \text { High-fat diet } \\ \text { LDL } & \text { low-density lipoprotein } \\ \text { NAFLD } & \text { nonalcoholic fatty liver disease } \\ \text { NEP } & \text { neprilysin } \\ \text { RAS } & \text { renin-angiotensin system } \\ \text { TG } & \text { triglyceride }\end{array}$

\section{References}

1. Lloyd-Jones, D.M. Cardiovascular Risk Prediction: Basic Concepts, Current Status, and Future Directions. Circulation 2010, 121, 1768-1777. [CrossRef] [PubMed]

2. Virmani, R.; Kolodgie, F.D.; Burke, A.P.; Farb, A.; Schwartz, S.M. Lessons from Sudden Coronary Death: A Comprehensive Morphological Classification Scheme for Atherosclerotic Lesions. Arter. Thromb. Vasc. Biol. 2000, 20, 1262-1275. [CrossRef] [PubMed]

3. Bentzon, J.F.; Otsuka, F.; Virmani, R.; Falk, E. Mechanisms of Plaque Formation and Rupture. Circ. Res. 2014, 114, 1852-1866. [CrossRef] [PubMed]

4. Libby, P.; Okamoto, Y.; Rocha, V.Z.; Folco, E. Inflammation in Atherosclerosis: Transition from Theory to Practice. Circ. J. Off. J. Jpn. Circ. Soc. 2010, 74, 213-220.

5. Targher, G. Non-Alcoholic Fatty Liver Disease, the Metabolic Syndrome and the Risk of Cardiovascular Disease: The Plot Thickens. Diabet. Med. J. Br. Diabet. Assoc. 2007, 24, 1-6. [CrossRef]

6. Cohen, J.C.; Horton, J.D.; Hobbs, H.H. Human Fatty Liver Disease: Old Questions and New Insights. Science 2011, 332, 1519-1523. [CrossRef]

7. Day, C.P.; James, O.F. Steatohepatitis: A Tale of Two “hits"? Gastroenterology 1998, 114, 842-845. [CrossRef]

8. Da Silva, A.R.; Fraga-Silva, R.A.; Stergiopulos, N.; Montecucco, F.; Mach, F. Update on the Role of Angiotensin in the Pathophysiology of Coronary Atherothrombosis. Eur. J. Clin. Investig. 2015, 45, 274-287. [CrossRef]

9. Santos, S.H.S.; Andrade, J.M.O. Angiotensin 1-7: A Peptide for Preventing and Treating Metabolic Syndrome. Peptides 2014, 59, 34-41. [CrossRef]

10. Keidar, S.; Attias, J.; Heinrich, R.; Coleman, R.; Aviram, M. Angiotensin II Atherogenicity in Apolipoprotein E Deficient Mice Is Associated with Increased Cellular Cholesterol Biosynthesis. Atherosclerosis 1999, 146, 249-257. [CrossRef]

11. Wei, Y.; Clark, S.E.; Morris, E.M.; Thyfault, J.P.; Uptergrove, G.M.E.; Whaley-Connell, A.T.; Ferrario, C.M.; Sowers, J.R.; Ibdah, J.A. Angiotensin II-Induced Non-Alcoholic Fatty Liver Disease Is Mediated by Oxidative Stress in Transgenic TG(mRen2)27(Ren2) Rats. J. Hepatol. 2008, 49, 417-428. [CrossRef]

12. Keidar, S.; Heinrich, R.; Kaplan, M.; Hayek, T.; Aviram, M. Angiotensin II Administration to Atherosclerotic Mice Increases Macrophage Uptake of Oxidized Ldl: A Possible Role for Interleukin-6. Arter. Thromb. Vasc. Biol. 2001, 21, 1464-1469. [CrossRef]

13. Nickenig, G.; Harrison, D.G. The AT(1)-Type Angiotensin Receptor in Oxidative Stress and Atherogenesis: Part I: Oxidative Stress and Atherogenesis. Circulation 2002, 105, 393-396. [CrossRef]

14. Wang, Y.; Tikellis, C.; Thomas, M.C.; Golledge, J. Angiotensin Converting Enzyme 2 and Atherosclerosis. Atherosclerosis 2013, 226, 3-8. [CrossRef]

15. Cao, X.; Yang, F.-Y.; Xin, Z.; Xie, R.-R.; Yang, J.-K. The ACE2/Ang-(1-7)/Mas Axis Can Inhibit Hepatic Insulin Resistance. Mol. Cell. Endocrinol. 2014, 393, 30-38. [CrossRef] 
16. Dong, B.; Zhang, C.; Feng, J.B.; Zhao, Y.X.; Li, S.Y.; Yang, Y.P.; Dong, Q.L.; Deng, B.P.; Zhu, L.; Yu, Q.T.; et al. Overexpression of ACE2 Enhances Plaque Stability in a Rabbit Model of Atherosclerosis. Arter. Thromb. Vasc. Biol. 2008, 28, 1270-1276. [CrossRef] [PubMed]

17. Thomas, M.C.; Pickering, R.J.; Tsorotes, D.; Koitka, A.; Sheehy, K.; Bernardi, S.; Toffoli, B.; Nguyen-Huu, T.P.; Head, G.A.; Fu, Y.; et al. Genetic Ace2 Deficiency Accentuates Vascular Inflammation and Atherosclerosis in the ApoE Knockout Mouse. Circ. Res. 2010, 107, 888-897. [CrossRef] [PubMed]

18. Cao, X.; Yang, F.; Shi, T.; Yuan, M.; Xin, Z.; Xie, R.; Li, S.; Li, H.; Yang, J.-K. Angiotensin-Converting Enzyme 2/Angiotensin(1-7)/Mas Axis Activates Akt Signaling to Ameliorate Hepatic Steatosis. Sci. Rep. 2016, 6, 1-11. [CrossRef] [PubMed]

19. Peregrine, A.S.; Mamman, M. Pharmacology of Diminazene: A Review. Acta Trop. 1993, 54, 185-203. [CrossRef]

20. Shenoy, V.; Gjymishka, A.; Jarajapu, Y.P.; Qi, Y.; Afzal, A.; Rigatto, K.; Ferreira, A.J.; Fraga-Silva, R.A.; Kearns, P.; Douglas, J.Y.; et al. Diminazene Attenuates Pulmonary Hypertension and Improves Angiogenic Progenitor Cell Functions in Experimental Models. Am. J. Respir. Crit. Care Med. 2013, 187, 648-657. [CrossRef] [PubMed]

21. Qaradakhi, T.; Gadanec, L.K.; McSweeney, K.R.; Tacey, A.; Apostolopoulos, V.; Levinger, I.; Rimarova, K.; Egom, E.E.; Rodrigo, L.; Kruzliak, P.; et al. The Potential Actions of Angiotensin-Converting Enzyme II (ACE2) Activator Diminazene Aceturate (DIZE) in Various Diseases. Clin. Exp. Pharm. Physiol. 2020, 47, 751-758. [CrossRef]

22. Bruce, E.B.; Sakarya, Y.; Kirichenko, N.; Toklu, H.Z.; Sumners, C.; Morgan, D.; Tümer, N.; Scarpace, P.J.; Carter, C.S. ACE2 Activator Diminazene Aceturate Reduces Adiposity but Preserves Lean Mass in Young and Old Rats. Exp. Gerontol. 2018, 111, 133-140. [CrossRef]

23. Joviano-Santos, J.V.; Santos-Miranda, A.; Joca, H.C.; Cruz, J.S.; Ferreira, A.J. Diminazene Aceturate (DIZE) Has Cellular and in Vivo Antiarrhythmic Effects. Clin. Exp. Pharm. Physiol. 2020, 47, 213-219. [CrossRef] [PubMed]

24. Thatcher, S.E.; Zhang, X.; Howatt, D.A.; Lu, H.; Gurley, S.B.; Daugherty, A.; Cassis, L.A. ACE2 Deficiency in Whole Body or Bone Marrow-Derived Cells Increases Atherosclerosis in LDL Receptor - / - Mice. Arter. Thromb. Vasc. Biol. 2011, 31, 758-765. [CrossRef]

25. Fraga-Silva, R.A.; Montecucco, F.; Costa-Fraga, F.P.; Nencioni, A.; Caffa, I.; Bragina, M.E.; Mach, F.; Raizada, M.K.; Santos, R.A.S.; da Silva, R.F.; et al. Diminazene Enhances Stability of Atherosclerotic Plaques in ApoE-Deficient Mice. Vasc. Pharm. 2015, 74, 103-113. [CrossRef] [PubMed]

26. Chawla, A. Control of Macrophage Activation and Function by PPARs. Circ. Res. 2010, 106, 1559-1569. [CrossRef] [PubMed]

27. Mosser, D.M.; Edwards, J.P. Exploring the Full Spectrum of Macrophage Activation. Nat. Rev. Immunol. 2008, 8, 958-969. [CrossRef] [PubMed]

28. Cho, K.Y.; Miyoshi, H.; Kuroda, S.; Yasuda, H.; Kamiyama, K.; Nakagawara, J.; Takigami, M.; Kondo, T.; Atsumi, T. The Phenotype of Infiltrating Macrophages Influences Arteriosclerotic Plaque Vulnerability in the Carotid Artery. J. Stroke Cereb. Dis. Off. J. Natl. Stroke Assoc. 2013, 22, 910-918. [CrossRef] [PubMed]

29. Hanna, R.N.; Shaked, I.; Hubbeling, H.G.; Punt, J.A.; Wu, R.; Herrley, E.; Zaugg, C.; Pei, H.; Geissmann, F.; Ley, K.; et al. NR4A1 (Nur77) Deletion Polarizes Macrophages toward an Inflammatory Phenotype and Increases Atherosclerosis. Circ. Res. 2012, 110, 416-427. [CrossRef]

30. Sharma, M.; Gupta, S.; Singh, K.; Mehndiratta, M.; Gautam, A.; Kalra, O.P.; Shukla, R.; Gambhir, J.K. Association of GlutathioneS-Transferase with Patients of Type 2 Diabetes Mellitus with and without Nephropathy. Diabetes Metab. Syndr. 2016. [CrossRef] [PubMed]

31. Cardilo-Reis, L.; Gruber, S.; Schreier, S.M.; Drechsler, M.; Papac-Milicevic, N.; Weber, C.; Wagner, O.; Stangl, H.; Soehnlein, O.; Binder, C.J. Interleukin-13 Protects from Atherosclerosis and Modulates Plaque Composition by Skewing the Macrophage Phenotype. EMBO Mol. Med. 2012, 4, 1072-1086. [CrossRef] [PubMed]

32. Wenzel, U.O.; Kintscher, U. ACE2 and SARS-CoV-2-Tissue or Plasma, Good or Bad? Am. J. Hypertens. 2021. [CrossRef]

33. Kuriakose, S.; Muleme, H.; Onyilagha, C.; Okeke, E.; Uzonna, J.E. Diminazene Aceturate (Berenil) Modulates LPS Induced pro-Inflammatory Cytokine Production by Inhibiting Phosphorylation of MAPKs and STAT Proteins. Innate Immun. 2013. [CrossRef] [PubMed]

34. Qaradakhi, T.; Gadanec, L.; Matsoukas, J.; Apostolopoulos, V.; Zulli, A. Could DIZE Be the Answer to COVID-19? Maturitas 2020, 140, 83-84. [CrossRef] [PubMed]

35. Feltenberger, J.D.; Andrade, J.M.O.; Paraíso, A.; Barros, L.O.; Filho, A.B.M.; Sinisterra, R.D.; Sousa, F.B.; Guimaraes, A.; De Paula, A.; Campagnole-Santos, M.; et al. Oral Formulation of Angiotensin-(1-7) Improves Lipid Metabolism and Prevents High-Fat Diet-Induced Hepatic Steatosis and Inflammation in Mice. Hypertension 2013, 62, 324-330. [CrossRef] [PubMed]

36. Moreira, C.C.L.; Lourenço, F.C.; Mario, É.G.; Santos, R.A.S.; Botion, L.M.; Chaves, V.E. Long-Term Effects of Angiotensin-(1-7) on Lipid Metabolism in the Adipose Tissue and Liver. Peptides 2017, 92, 16-22. [CrossRef]

37. Sutherland, T.E. Chitinase-like Proteins as Regulators of Innate Immunity and Tissue Repair: Helpful Lessons for Asthma? Biochem. Soc. Trans. 2018, 46, 141-151. [CrossRef] [PubMed]

38. Rőszer, T. Understanding the Mysterious M2 Macrophage through Activation Markers and Effector Mechanisms. Available online: https: / / www.hindawi.com/journals/mi/2015/816460/ (accessed on 16 November 2020).

39. Murakami, S. Taurine and Atherosclerosis. Amino Acids 2014, 46, 73-80. [CrossRef] 
40. Murakami, S.; Ono, A.; Kawasaki, A.; Takenaga, T.; Ito, T. Taurine Attenuates the Development of Hepatic Steatosis through the Inhibition of Oxidative Stress in a Model of Nonalcoholic Fatty Liver Disease in Vivo and in Vitro. Amino Acids 2018, 50, 1279-1288. [CrossRef]

41. Lin, S.; Hirai, S.; Yamaguchi, Y.; Goto, T.; Takahashi, N.; Tani, F.; Mutoh, C.; Sakurai, T.; Murakami, S.; Yu, R.; et al. Taurine Improves Obesity-Induced Inflammatory Responses and Modulates the Unbalanced Phenotype of Adipose Tissue Macrophages. Mol. Nutr. Food Res. 2013, 57, 2155-2165. [CrossRef]

42. Sartório, C.L.; Pimentel, E.B.; dos Santos, R.L.; Rouver, W.N.; Mill, J.G. Acute Hypotensive Effect of Diminazene Aceturate in Spontaneously Hypertensive Rats: Role of NO and Mas Receptor. Clin. Exp. Pharm. Physiol. 2020, 47, 1723-1730. [CrossRef]

43. Guizoni, D.M.; Vettorazzi, J.F.; Carneiro, E.M.; Davel, A.P. Modulation of Endothelium-Derived Nitric Oxide Production and Activity by Taurine and Taurine-Conjugated Bile Acids. Nitric Oxide Biol. Chem. 2020, 94, 48-53. [CrossRef] [PubMed]

44. Chen, X.; Qiu, L.; Li, M.; Dürrnagel, S.; Orser, B.A.; Xiong, Z.-G.; MacDonald, J.F. Diarylamidines: High Potency Inhibitors of Acid-Sensing Ion Channels. Neuropharmacology 2010, 58. [CrossRef]

45. Velkoska, E.; Patel, S.K.; Griggs, K.; Pickering, R.J.; Tikellis, C.; Burrell, L.M. Short-Term Treatment with Diminazene Aceturate Ameliorates the Reduction in Kidney ACE2 Activity in Rats with Subtotal Nephrectomy. PLoS ONE 2015, 10, e0118758. [CrossRef] [PubMed]

46. Haber, P.K.; Ye, M.; Wysocki, J.; Maier, C.; Haque, S.K.; Batlle, D. ACE2-Independent Action Of Presumed ACE2 Activators: Studies In Vivo, Ex Vivo and In Vitro. Hypertension 2014, 63, 774-782. [CrossRef] [PubMed]

47. Mamman, M.; Gettinby, G.; Murphy, N.B.; Kemei, S.; Peregrine, A.S. Frequency of Diminazene-Resistant Trypanosomes in Populations of Trypanosoma Congolense Arising in Infected Animals Following Treatment with Diminazene Aceturate. Antimicrob. Agents Chemother. 1995, 39, 1107-1113. [CrossRef] [PubMed]

48. Stachowicz, A.; Wiśniewska, A.; Kuś, K.; Kiepura, A.; Gębska, A.; Gajda, M.; Białas, M.; Totoń-Żurańska, J.; Stachyra, K.; Suski, M.; et al. The Influence of Trehalose on Atherosclerosis and Hepatic Steatosis in Apolipoprotein E Knockout Mice. Int. J. Mol. Sci. 2019, 20, 1552. [CrossRef]

49. Suski, M.; Kiepura, A.; Wiśniewska, A.; Kuś, K.; Skałkowska, A.; Stachyra, K.; Stachowicz, A.; Gajda, M.; Korbut, R.; Olszanecki, R. Anti-Atherosclerotic Action of GW9508-Free Fatty Acid Receptors Activator-In apoE-Knockout Mice. Pharm. Rep. Pr. 2019, 71, 551-555. [CrossRef]

50. Stachowicz, A.; Olszanecki, R.; Suski, M.; Wiśniewska, A.; Totoń-Żurańska, J.; Madej, J.; Jawień, J.; Białas, M.; Okoń, K.; Gajda, M.; et al. Mitochondrial Aldehyde Dehydrogenase Activation by Alda-1 Inhibits Atherosclerosis and Attenuates Hepatic Steatosis in Apolipoprotein E-Knockout Mice. J. Am. Heart Assoc. 2014, 3, e001329. [CrossRef]

51. Wiśniewski, J.R.; Zougman, A.; Mann, M. Combination of FASP and StageTip-Based Fractionation Allows in-Depth Analysis of the Hippocampal Membrane Proteome. J. Proteome Res. 2009, 8, 5674-5678. [CrossRef]

52. Wiśniewski, J.R.; Rakus, D. Multi-Enzyme Digestion FASP and the "Total Protein Approach"-based Absolute Quantification of the Escherichia Coli Proteome. J. Proteom. 2014, 109, 322-331. [CrossRef] [PubMed]

53. Taverner, T.; Karpievitch, Y.V.; Polpitiya, A.D.; Brown, J.N.; Dabney, A.R.; Anderson, G.A.; Smith, R.D. DanteR: An Extensible R-Based Tool for Quantitative Analysis of -Omics Data. Bioinforma. Oxf. Engl. 2012, 28, 2404-2406. [CrossRef] [PubMed] 